https://helda.helsinki.fi

\title{
The use of multiple cues in mate choice
}

\section{Candolin, Ulrika}

Cambridge University Press 2003-11

Biological Reviews 78 (4): 575-595

http://hdl.handle.net/1975/138

Downloaded from Helda, University of Helsinki institutional repository.

This is an electronic reprint of the original article.

This reprint may differ from the original in pagination and typographic detail.

Please cite the original version. 


\title{
The use of multiple cues in mate choice
}

\section{ULRIKA GANDOLIN}

\author{
Department of Ecology and Systematics, P.O. Box 65, University of Helsinki, Helsinki FIN-00014, Finland \\ (e-mail: ulrika.candolin@helsinki.fi)
}

(Received 28 February 2002; revised 12 December 2002; accepted 18 December 2002)

\begin{abstract}
An increasing number of studies find females to base their mate choice on several cues. Why this occurs is debated and many different hypotheses have been proposed. Here I review the hypotheses and the evidence in favour of them. At the same time I provide a new categorisation based on the adaptiveness of the preferences and the information content of the cues. A few comparative and empirical studies suggest that most multiple cues are Fisherian attractiveness cues or uninformative cues that occur alongside a viability indicator and facilitate detection, improve signal reception, or are remnants from past selection pressures. However, much evidence exists for multiple cues providing additional information and serving as multiple messages that either indicate general mate quality or enable females that differ in mate preferences to choose the most suitable male. Less evidence exists for multiple cues serving as back-up signals. The importance of receiver psychology, multiple sensory environments and signal interaction in the evolution of multiple cues and preferences has received surprisingly little attention but may be of crucial importance. Similarly, sexual conflict has been proposed to result in maladaptive preferences for manipulative cues, and in neutral preferences for threshold cues, but no reliable evidence exists so far. An important factor in the evolution of multiple preferences is the cost of using additional cues. Most theoretical work assumes that the cost of choice increases with the number of cues used, which restricts the conditions under which preferences for multiple cues are expected to evolve. I suggest that in contrast to this expectation, the use of multiple cues can reduce mate choice costs by decreasing the number of mates inspected more closely or the time and energy spent inspecting a set of mates. This may be one explanation for why multiple cues are more common than usually expected. Finally I discuss the consequences that the use of multiple cues may have for the process of sexual selection, the maintenance of genetic variation, and speciation.
\end{abstract}

Key words: amplifiers, mate choice costs, mate preferences, multicomponent signals, multiple ornaments, receiver psychology, sexual selection, signal interaction, unreliable signals, viability indicators.

\section{GONTENTS}

I. Introduction

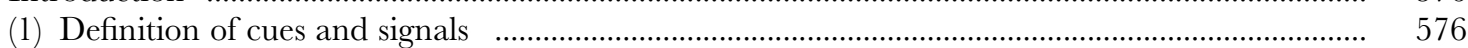

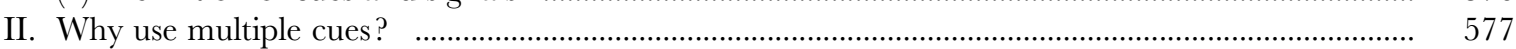

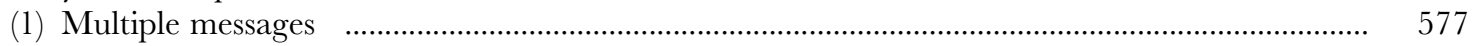

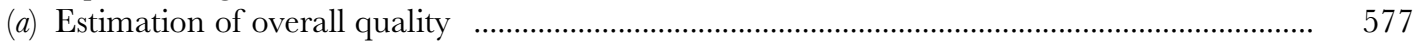

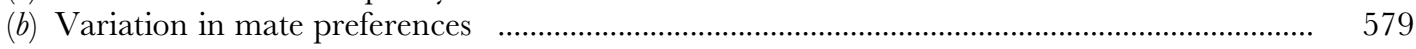

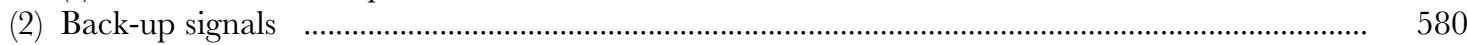

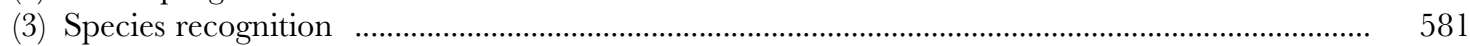

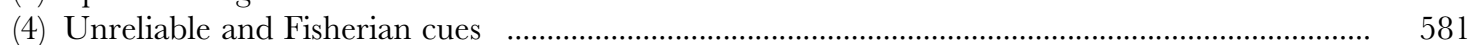

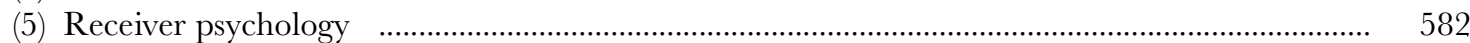

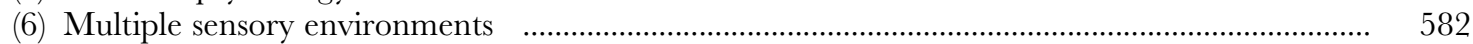

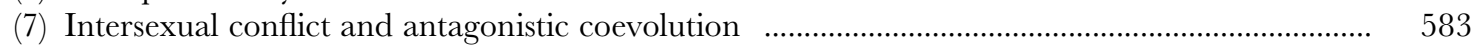

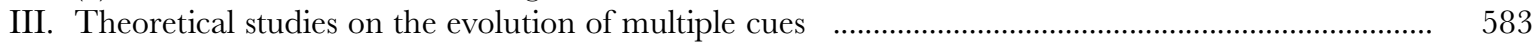

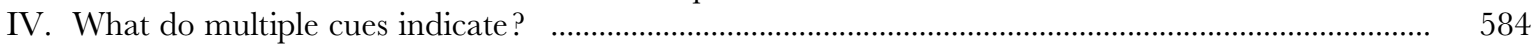

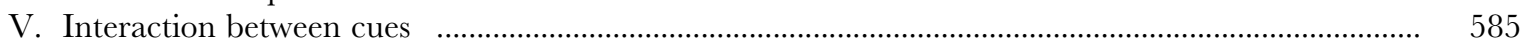


VI. Evolution of multiple preferences and cues ……………………………….................................. 587

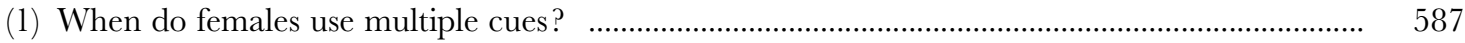

(2) Increased or decreased costs of choice? …………….............................................................. 587

VII. Consequences of the use of multiple cues …………………………………………………........... 588

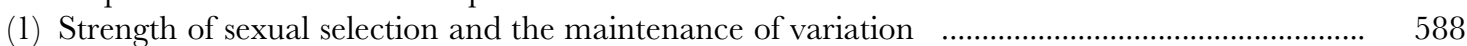

(2) Speciation and the evolution of alternative signalling tactics _.................................................. 589

VIII. Conclusions and directions for future research …………............................................................... 589

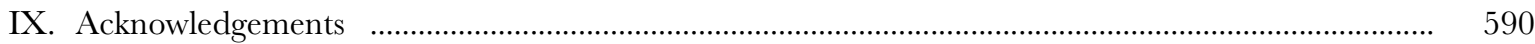

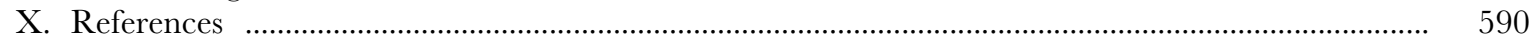

\section{INTRODUGTION}

The possibility that mate choice is based on several cues, instead of on one, has received increased attention in recent years. Sexual displays are often highly complex, involving many different signal components. For example, in bird species males are often both brightly ornamented and perform an elaborate song, whereas many fish species combine bright colours with conspicuous courtship displays. In addition, males of several species offer some resource to the female, such as a territory or a nest, which may be used as a cue in female mate choice. The picture is further complicated when the complexity of mate choice behaviour is considered. Recent studies show that females may emphasise different cues in different contexts, they may vary in the attention they pay to different cues or in the number of cues that they evaluate, and that interaction between cues may obscure preferences for single cues (Jennions \& Petrie, 1997; Møller et al., 1998; KodricBrown \& Nicoletto, $2001 b$ ).

To explain how mating preferences arise and select for sexual signals in the opposite sex, three main mechanisms have been proposed: (1) direct fitness benefits of choice, such as improved parental care that enhances offspring survival (Hoelzer, 1989); (2) indirect genetic benefits in the form of the inheritance of genes for viability (Zahavi, 1975) and attractiveness [the runaway process of Fisher (1930)]; and (3) exploitation of preexisting sensory biases in the receiver (Ryan \& Rand, $1993 a$; Endler \& Basolo, 1998). These mechanisms may work either alone or in combination in the evolution of sexual signals. Preferences for multiple signals may arise through a single preference selecting for multiple signals or, alternatively, through multiple preferences each coevolving with a signal (Brooks \& Couldridge, 1999). Recently, a new model was proposed by Holland \& Rice(1998), the antagonistic chase-awayselection, which proposes that resistance instead of preference can select for exaggerated display traits and generate mating biases. The model is, however, an extension of earlier models, as both fitness benefits and sensory exploitation are invoked (Rosenthal \& Servedio, 1999; Getty, 1999; Rice \& Holland, 1999), and as resistance can be described as cryptic preference (Kokko et al., 2003).

But why should females, and sometimes males, use multiple cues instead of one cue? Different hypotheses have been put forward, some of which have received empirical support, but their generality remains unknown. Here I review the latest progress in the study of the use of multiple cues in mate choice and consider the plausibility and generality of the proposed hypotheses. In addition, I discuss the consequences that the use of multiple cues may have for the process of sexual selection and the maintenance of genetic variation, and the role that multiple cues may play in speciation. The aim is to provide a picture of the present state of the field, to clarify confusing topics, to categorise the presented hypotheses, and to point out areas where more studies are needed. To avoid repetition, I have omitted several interesting studies with similar conclusions and instead given more details for a few exemplifying studies.

\section{(1) Definition of cues and signals}

Cues are traits that are assessed during mate choice and influence the mating decision. They can be phenotypic traits (morphological, acoustic, olfactory, tactile or behavioural traits) or resources defended or produced by the signaller, such as a nest or a territory. The traits can arise in another context than communication and be maintained due to other selection pressures than selection for communication. For example, body constitution and running speed may be under survival selection but simultaneously be used as indicators of fitness. However, often the traits have been modified for communication, or serve a function in communication only, such as colourful ornaments or courtship behaviours that are detrimental to survival but increase attractiveness to the opposite sex.

Cues that have at least partly been modified by natural selection for the purpose of communication are termed signals and, thus, form a special type of cue. 
Signals can consist of one cue or, alternatively, of several cues (components) that are evaluated together as one signal, such as displays combining visual and acoustic components. Signals that are made up of several components are called multicomponent signals, or multimodal signals if the components occur in several sensory modalities. Signals are under different selective pressures to other traits, due to the dual interaction between signallers and receivers. Properties of the receiver exert selective pressures on signal design by favouring signallers who elicit favourable responses. At the same time signal design exerts reciprocal selective pressures on receiver behaviour by favouring receivers who can accurately deduce the nature and intentions of signallers (Johnstone, 1997).

\section{WHY USE MULTIPLE GUES?}

The use of multiple cues in mate choice may: (1) be adaptive and increase fitness by reducing mate choice errors or costs of choice; (2) have no influence on fitness but include preferences that are remnants from past selection or have arisen in another context and are exploited by the signaller; or (3) be maladaptive and decrease fitness, as the signaller manipulates mating resistance of the receiver by taking advantage of preexisting sensory biases (Table 1). Fitness benefits can be gained either directly, through effects on fecundity, survival and future reproductive opportunities, or indirectly through the inheritance of genes that increase offspring viability or attractiveness.

Cues can be further grouped into two groups depending on their information content: (a) informative and (b) uninformative cues (Table 1). Informative cues provide information about mate quality, the species or the resources offered. This can reduce mate choice errors or the cost at which the information is gained by reducing time or energy expenditure or mortality risk. Uninformative cues are unreliable indicators of mate quality but can belong to any of the three groups detailed above: they can increase receiver fitness by facilitating detection or signal assessment, have no effect on fitness, or decrease receiver fitness if the signaller manipulates mating resistance of the receiver. Cues whose use are harmful to the receiver do, in fact, indicate a harmful mate, but the receiver is not able to receive this information as the cues exploit pre-existing sensory biases. The cues are therefore uninformative of mate quality to the receiver.

Hypotheses relating to the group of adaptive preferences for informative cues include the multiple messages hypothesis, the backup hypothesis (or redundant signal hypothesis) (Møller \& Pomiankowski, 1993; Johnstone, 1997), the species recognition hypothesis (Pfennig, 1998), and the hypothesis of Fisherian cues that reflect indirect genetic benefits (Pomiankowski \& Iwasa, 1993). Hypotheses relating to the group of adaptive preferences for uninformative cues, include the receiver psychology hypothesis (Rowe, 1999) and the hypothesis of unreliable cues that exploit preexisting sensory biases of the receiver but still are beneficial to the receiver (Ryan \& Rand, 1993a). The hypotheses of multiple sensory environments can belong to either group, as some cues may facilitate detection or signal transmission whereas others reflect mate quality.

Non-adaptive preferences for uninformative cues that have no effect on receiver fitness can be explained by the hypotheses of unreliable and threshold cues (Møller \& Pomiankowski, 1993; Holland \& Rice, 1998). Maladaptive preferences that have a detrimental effect on receiver fitness can be explained by intersexual conflict (Holland \& Rice, 1998). In the following sections I will review the different hypotheses and evidence for and against them to give an overview of the current state of the field.

\section{(1) Multiple messages}

According to the multiple messages hypothesis, different signals give information about different mate qualities (Møller \& Pomiankowski, 1993; Johnstone, 1997). The signals may then be evaluated together to indicate the general quality of the mate, or alternatively, different receivers may pay attention to different signals and, thus, to different aspects of mate quality, according to their own condition or genetic make-up (Wedekind, 1992).

\section{(a) Estimation of overall quality}

To gain information on the overall quality of a potential mate an individual may pay attention to several traits that reflect different qualities. In support of this, several studies have found different ornaments to reflect different aspects of mate quality. For example, ornamental colours that are made up of different pigments often reflect different qualities; carotenoid pigments usually reflect physical condition (Hill \& Montgomerie, 1994; Linville \& Breitwisch, 1997; Olson \& Owens, 1998; McGraw \& Hill, 2000), especially disease condition (reviewed by Møller et al., 2000), whereas melanin-based colours mostly reflect social status (reviewed in Senar, 1999; but see Fitze \& Richner, 2002). An example of this is the ornamentation of the American goldfinch (Carduelis tristis) where 
Table 1. Categorisation of the hypotheses put forward to explain the use of multiple cues in mate choice

\begin{tabular}{|c|c|c|c|c|}
\hline $\begin{array}{l}\text { Adaptiveness of } \\
\text { preferences }\end{array}$ & Form of cues & Proposed hypotheses & Purpose of different cues & $\begin{array}{l}\text { Proximate benefit } \\
\text { gained by the receiver }\end{array}$ \\
\hline \multirow[t]{7}{*}{$\begin{array}{l}\text { Adaptive, increase } \\
\text { fitness through less } \\
\text { errors or lower costs } \\
\text { of mate choice }\end{array}$} & \multirow[t]{4}{*}{ Informative cues } & Multiple messages & $\begin{array}{l}\text { Indicator traits that reflect } \\
\text { different qualities } \\
\text { - Sensitive to different } \\
\text { environmental or } \\
\text { intrinsic factors } \\
\text { - Develop at different times }\end{array}$ & $\begin{array}{l}\text { - Evaluated together the traits } \\
\text { reflect overall quality } \\
\text { - Individuals can emphasise the cue } \\
\text { that is most relevant for them }\end{array}$ \\
\hline & & Back-up cues & $\begin{array}{l}\text { Indicator traits that reflect } \\
\text { the same quality }\end{array}$ & Increased accuracy of assessment \\
\hline & & Species recognition & $\begin{array}{l}\text { Different cues for species } \\
\text { recognition and mate assessment }\end{array}$ & $\begin{array}{l}\text { Avoidance of costly matings with } \\
\text { other species }\end{array}$ \\
\hline & & Fisherian cues & Indicate heritable attractiveness & Offspring inherit the attractive trait \\
\hline & \multirow[t]{2}{*}{ Uninformative cues } & Unreliable cues & $\begin{array}{l}\text { Exploitation of sensory } \\
\text { biases in the receiver }\end{array}$ & Facilitates detection of the signaller \\
\hline & & Receiver psychology & $\begin{array}{l}\text { Additional cues enhance } \\
\text { detectability, discriminability } \\
\text { or memorability of the signal }\end{array}$ & Facilitates mate assessment \\
\hline & $\begin{array}{l}\text { Informative or } \\
\text { uninformative cues }\end{array}$ & $\begin{array}{l}\text { Multiple sensory } \\
\text { environments }\end{array}$ & $\begin{array}{l}\text { Indicator or unreliable } \\
\text { cues that are used: } \\
\text { - At different distances } \\
\text { - At different stages of the } \\
\text { courtship ritual } \\
\text { - In different signal } \\
\text { transmission habitats }\end{array}$ & $\begin{array}{l}\text { Facilitates mate assessment or } \\
\text { increases the amount of } \\
\text { information gained }\end{array}$ \\
\hline $\begin{array}{l}\text { Non-adaptive, no } \\
\text { effect on fitness }\end{array}$ & Uninformative cues & $\begin{array}{c}\text { Unreliable cues, } \\
\text { threshold cues }\end{array}$ & $\begin{array}{l}\text { - Exploitation of sensory } \\
\text { biases in the receiver } \\
\text { - Remnants from past selection }\end{array}$ & \\
\hline $\begin{array}{l}\text { Maladaptive, } \\
\text { reduce fitness }\end{array}$ & $\begin{array}{l}\text { Uninformative, } \\
\text { manipulating cues }\end{array}$ & Intersexual conflict & $\begin{array}{l}\text { Manipulation of mating } \\
\text { resistance by exploitation } \\
\text { of pre-existing sensory biases }\end{array}$ & \\
\hline
\end{tabular}


carotenoid-based plumage and bill coloration are sensitive to infection by intestinal coccidians, whereas the melanin-based black cap is not but instead may be shaped by social interactions (McGraw \& Hill, 2000). This difference in information content may be due to the fact that the nutrients required to maintain the two colours are different. Melanins are synthesised from amino acids that are basic dietary components and usually not a limiting resource (Fox, 1976). Carotenoids, on the other hand, cannot be synthesised by vertebrates but have to be ingested with the food and may be a limiting resource and therefore reflect condition (Goodwin, 1984). Thus, differences in the sensitivity of traits to environmental conditions and properties of the male can result in different traits signalling different qualities.

Different patches of the same colour can also differ in their information content. In the greenfinch (Carduelis chloris) the brightness of yellow wing patches reflects age whereas yellow tail patches reflect the ability to resist parasites, measured as virus clearance rate (Lindström \& Lundström, 2000). Even different characteristics of a single ornament may provide different information, such as in the roach (Rutilis rutilis) where the number and height of breeding tubercles on different body parts give information about infection with two different parasites, Diplozoon sp. and nematodes (Wedekind, 1992). Wedekind (1992) explained this with the ornaments being determined by a mix of sexual hormones that regulated the allocation of energy into different parts of the immune system depending on parasite burden. Taken together, these studies suggest that traits that are traditionally evaluated as one trait, such as ornamental coloration, song quality, or courtship behaviour, could consist of several components that each bear their own message about some aspect of quality and that give a clearer indication of mate quality when evaluated together. One may wonder how often we miss multiple messages by measuring traits as single entities.

Another possibility is that ornaments indicate condition over different time scales, with some signals reflecting condition over long time scales while others are more dynamic and respond to short-term changes in condition (e.g. Sorenson \& Derrickson, 1994; Møller et al., 1998; Hill et al., 1999). For example, Birkhead, Fletcher \& Pellatt (1998) found two sexual signals of zebra finches (Taeniopygia guttata), song rate and beak colour, to be uncorrelated after 11 weeks of food and exercise manipulation in the laboratory. This was probably due to the two traits reacting to changes in condition at different rates, song rate responded quickly and indicated present condition whereas beak colour took longer to change and probably reflected condition over a longer time scale. Earlier studies had found the two traits to be correlated when birds were maintained under favourable conditions and the differences between past and present condition were smaller (Houtman, 1992; Collins, Hubbard \& Houtman, 1994). Similarly, different components of the calling song of field crickets (Gryllus campestris) reflect condition during different stages of the lifetime; call rate, chirp rate and interchirp duration reflect current nutritional intake, whereas carrier frequency reflects past growth and juvenile development (Scheuber, Jacot \& Brinkhof, 2003). An untested possibility is that ornaments that develop over long time periods are good indicators of genetic quality, whereas flexible signals that reflect present condition may be better indicators of direct benefits such as parenting ability or fertilisation success.

\section{(b) Variation in mate preferences}

The possibility that females differ in the attention they pay to different mate qualities and therefore in how they weigh different signals has received relatively little attention. There are some indications that different signals are evaluated differently depending on whether females are choosing direct or genetic benefits. In birds, song repertoire has been proposed to be used as a cue in extra-pair mate choice and to indicate the genetic quality of the male, whereas territory characteristics may be more important in the choice of a social mate and to indicate the parenting ability of the male (Searcy, 1992). This is supported by a study on the great reed warbler, Acrocephalus arundinaceus, where cuckolded males had smaller song repertoires than their cuckolders and song repertoire correlated positively with offspring survival (Hasselquist, Bensch \& von Schantz, 1996). Similarly, the forehead patch in collared flycatchers (Ficedula albicollis) - an ornamental trait that indicates genetic quality (Sheldon et al., 1997) - was wider in cuckolding males than in the males they cuckolded, whereas wing patch size-another sexual character that was uncorrelated to forehead patch width - did not differ significantly between cuckolded and cuckolding males (Sheldon \& Ellegren, 1999). A further possibility is that the attention females pay to direct and indirect benefits when choosing a social mate varies depending on the quality of the females and their ability to compensate for reductions in male parental care or amount of resources provided (Burley, 1986; Sheldon, 2000). High quality barn swallow females (Hirundo rustica) that breed early have 
been found to pair with long-tailed males who are of high genetic quality but build poor nests (Soler et al., 1998). Females of lower quality, who breed later, pair with males with shorter tails but with a higher nestbuilding effort.

Large variation in female preferences also exists in species where females mainly choose genetic benefits, such as in lekking species (Jennions \& Petrie, 1997; Widemo \& Saether, 1999). Variation in female preferences could then arise due to genetic differences, different developmental trajectories or environmental factors. The possibility of genotype-dependent mate preferences, with females preferring males that complement their own genetic make-up, has received much interest in recent years (see review by Tregenza \& Wedell, 2000). However, surprisingly little empirical evidence exists, relying on only a few studies on major histocompatibility complex (MHC)-based and $t$-complex-based mate choice (Williams \& Lenington, 1993; Penn \& Potts, 1999; Landry et al., 2001). Other factors that have been found to influence mating preferences, for direct or genetic benefits, are life-history stage, age, condition and costs of choice in terms of time and energy expenditure and loss of future reproductive opportunities (reviewed by Jennions \& Petrie, 1997). Kodric-Brown \& Nicoletto (2001 a) showed that in guppies (Poecilia reticulata) female preferences for the ornamental coloration of males change with age so that older females are less selective in relation to colour than younger females. In the threespine stickleback (Gasterosteus aculeatus), Luttbeg et al. (2001) demonstrated that a time constraint influences female preferences for cues used at the beginning of the mate choice process, whereas an energy constraint influences preferences expressed at the end of the choice process.

A few studies show that varying social and physical environments, such as predation risk and dominance hierarchies, can affect preferences for multiple cues (Reid \& Weatherhead, 1990; Kodric-Brown, 1993; Endler \& Houde, 1995; Marchetti, 1998). In the guppy, for example, females decrease the attention paid to ornamental traits when agonistic interactions among males become more frequent, while behavioural traits that indicate dominance increase in importance (Kodric-Brown, 1993). A further, untested possibility is that preferences depend on the environment that the offspring are expected to encounter. Different pheno- and genotypes may be favoured under different environmental conditions. This could favour flexible preferences that are adjusted to the expected conditions, presuming that the conditions can be predicted reliably enough.

\section{(2) Back-up signals}

The back-up signal (or redundant signal) hypothesis proposes that multiple signals allow a more accurate assessment of mate quality as each signal reflects the same quality with some error (Møller \& Pomiankowski, 1993; Johnstone, 1997). The hypothesis differs from the multiple messages hypothesis in that different signals reflect the same aspect of quality instead of different aspects. The use of back-up signals of quality may reduce mate choice errors or, alternatively, the time and energy spent inspecting mates if multiple back-up cues facilitate the detection of differences among mates. In addition, multiple back-up cues may make it more difficult for mates to cheat about their quality. Some degree of dishonesty is expected in stable signalling systems (Dawkins \& Guilford, 1991; Johnstone \& Grafen, 1993; Johnstone, 1994) and can be promoted by factors such as individual differences in costs of signalling. Differences in signalling costs can arise through individual differences in the allocation of resources to signalling and other fitness traits, such as parental effort or survival (Kokko, 1998; Candolin, 1999, 2000; Backwell et al., 2000; Møller \& Jennions, 2001). The use of multiple signals could facilitate the detection of cheaters if the expression of several dishonest signals is prevented by the different costs imposed by the different traits, or if the total cost of expressing multiple traits enforces honesty across traits.

Separating the back-up hypothesis from the multiple messages hypothesis can be difficult, as traits that signal different aspects of quality (multiple messages) can be correlated with overall quality and thereby serve as back-up signals of the overall quality of an individual. For example, in two antelopes, puku (Kobus vardoni) and topi (Damaliscus lunatus) male traits and territory characteristics are intercorrelated and may serve as back-up signals of male quality. At the same time the two cues signal different types of benefit to the female and serve as multiple messages; territories reflect food quality and predation risk, whereas male traits reflect phenotypic and probably genetic quality of the partner (Balmford, Rosser \& Albon, 1992). A correlation between male phenotypic traits and territory characteristics (or nest or other resource characteristics) has been found in several species, which implies that male and territory (resource) traits often back each other up as signals of male quality (e.g. Price, 1984; Kvarnemo, 1995; Bart \& Earnst, 1999; Candolin \& Voigt, 2001). However, the opposite result is equally common (e.g. Alatalo, Lundberg \& Glynn, 1986; Reid \& Weatherhead, 1990; Carranza, 1995; Buchanan \& Catchpole, 1997; Goulet, 1998; Soler et al., 1998), which indicates 
that a correlation between the traits is not a general trend.

Surprisingly few studies have presented significant positive correlations among male traits. Most evidence exists for the correlation between trait size and symmetry (e.g. Møller \& Swaddle, 1997; Badyaev et al., 1998; Thornhill \& Møller, 1998). Instead, the majority of studies have found multiple traits to be uncorrelated (e.g. Zuk et al., 1990; Birkhead et al., 1998; Marchetti, 1998; Kraak, Bakker \& Mundwiler, 1999; Badyaev et al., 2001, and references above). This suggests that back-up signals are less common than multiple messages, or, alternatively, that cues that do not indicate mate quality are common. A comprehensive comparative study is needed to investigate this.

\section{(3) Species recognition}

Sexual signals are often assumed to play a role both in species recognition and in mate assessment (reviewed by Andersson, 1994). This stems from a view of a continuum between sexual selection and species recognition, with behavioural isolation between species evolving as a consequence of sexual selection within species (Lande, 1981; Lande \& Kirkpatrick, 1988; Turner \& Burrow, 1995).

However, this view may not always hold. A recent review by Bennett \& Owens (2002) found no supportive evidence for variation in the form of sexual ornaments between species being due to sexual selection. Moreover, a study on Drosophila showed that a novel sexually selected trait may not necessarily contribute to species recognition; the broad male head of $D$. heteroneura is a novel sexual dimorphism that is sexually selected but not involved in behavioural isolation from the close relative D. silvestris (Boake, de Angelis \& Andreadis, 1997). Instead, additional cues are probably used to prevent hybridisation. In treefrogs Hyla versicolor and Hyla chrysoscelis, work by Gerhardt and co-workers (reviewed in Gerhardt, 2001) demonstrated that females use different cues for species recognition and mate assessment; call pulse rate is used for species recognition whereas call duration, which reflects male genetic quality (Welch, Semlitsch \& Gerhardt, 1998), is used for mate assessment.

Sexual selection and species recognition can also be in conflict if sexual selection preferences overlap with traits found in heterospecifics (Gerhardt, 1982; Rand, Ryan \& Wilczynski, 1992; Ryan \& Rand, 1993 b; Pfennig, 1998, 2000). For example, in the pygmy swordtail (Xiphophorus pygmaeus), females use body size as a mate-assessment cue and vertical bars as a species recognition cue (Hankinson \& Morris, 2002). These cues may lead to a preference for heterospecifics, as females prefer the large-bodied heterospecifics (Ryan \& Wagner, 1987) and some heterospecifics are heteromorphic for bars. Females then have to use additional specific cues in mate choice, such as chemical cues, to prevent hybridisation (Crapon de Caprona \& Ryan, 1990).

\section{(4) Unreliable and Fisherian cues}

Cues that do not indicate mate viability or direct benefits, but which take advantage of arbitrary preference or facilitate signal detection and assessment, have traditionally been termed 'unreliable' cues (Møller \& Pomiankowski, 1993). This includes cues that arise through Fisherian runaway process (Fisher, 1930), that exploit sensory biases in the receiver (Ryan \& Rand, 1993 a), or are remnants from past selection (Holland \& Rice, 1998). However, the term 'unreliable' is misleading for Fisherian attractiveness traits, as the traits do indicate heritable genetic quality (attractiveness) and increased reproductive value of offspring (see Eshel, Volovik \& Sansone, 2000; Kokko et al., 2002).

Unreliable, or uninformative, cues that do not indicate mate quality can incur fitness benefits to the receiver if they facilitate detection or signal reception and thereby reduce mate choice costs or errors. Alternatively, preferences for uninformative traits may incur no fitness benefits but be remnants from past selection, in which case the cues may need to exceed a threshold before attention is paid to other cues. Whether the use of uninformative cues in mate choice is adaptive or not to the receivers is, however, often unknown.

A theoretical study by Iwasa \& Pomiankowski (1994) indicated that Fisherian attractiveness traits are likely to evolve alongside a trait that indicates viability. Furthermore, a model by Holland \& Rice (1998) suggested that antagonistic coevolution between the sexes may result in several costly male display traits that have little value as indicators of quality but are maintained as thresholds for maintaining female interest. These models suggest that many multiple signals may not reflect viability but be Fisherian attractiveness traits or uninformative threshold traits that are remnants from past selection.

Indications of the commonness of Fisherian and uninformative cues have been found in comparative studies of birds. Møller \& Pomiankowski (1993) found the size of feather ornaments to be negatively related to asymmetry in species with one single ornament but not in species with multiple ornaments. This indicated that single ornaments are condition-dependent 
whereas multiple ornaments usually are not. Prum (1997) investigated the diversity of male traits in a clade of lekking bird species, manakins, and found the macroevolutionary pattern to be consistent with the predictions of Fisherian and sensory bias mechanisms. Manakin trait repertoire is very diverse, composed of multiple, hierarchically distributed traits that have evolved independently at various times in the history of manakin lineages, which supports an unconstrained evolutionary process. Moreover, a few empirical studies have found traits that are less important in mate choice to occur beside a single decisive trait, which suggests that they could be Fisherian or uninformative cues (Zuk et al., 1990; Ligon \& Zwartjes, 1995; Omland, $1996 a, b)$.

On the other hand, the frequent observation that multiple cues indicate some aspect of mate quality refutes the assumption that most cues are uninformative. This could, however, be due to a publication bias if studies that find multiple cues to indicate quality are submitted for publication and published more often than studies that find no correlation between mate quality and multiple cues. Another problem is that the quality that a cue reflects may be difficult to identify, which may result in an indicator trait mistakenly being classified as an uninformative cue. Moreover, some cues may have a dual function and facilitate detection and signal assessment while they also are heritable and indicate indirect genetic benefits.

\section{(5) Receiver psychology}

Due to receiver psychology, multicomponent signals that consist of several components may elicit greater responses than signals that consist of one component alone (Guilford \& Dawkins, 1991, 1993; Rowe, 1999). Therefore, signallers may produce multicomponent displays to enhance detection, recognition, discrimination or memorability of the signal. This possibility has received little consideration in studies on the evolution of signals. However, a recent review suggests that receiver psychology may play an important role in signal evolution (Rowe, 1999). Evidence exists for two stimuli to be more effective than one in eliciting responses from receivers (e.g. Green, 1964; Hultsch, Schleuss \& Todt, 1999; Rowe, 2002). This supports the notion that receiver psychology could influence signal design and evolution. However, it does not exclude the possibility that adaptive reasons (increased fitness of the receiver) have contributed to the evolution of preferences for multiple cues.

Multicomponent signals can improve detection of the signal by reducing reaction time, increasing probability of detection or lowering detection threshold. Discriminability may improve through better recognition, faster discrimination learning and multidimensional generalisation. Moreover, associative learning may be facilitated (reviewed by Rowe, 1999). However, so far most examples on the importance of receiver psychology on signal design and evolution are on signals other than sexual signals, such as warning and agonistic signals. Nevertheless, it is likely that the same benefits of multicomponency that apply to these signals could apply to sexual signals.

Signallers can improve signal reception both through the production of complementary components that require the same response from receivers, or through the production of noninformative accessory stimuli alongside the original message (Rowe, 1999). Components of a signal that do not convey any information about mate quality but produce a noninformative accessory stimulus perform an important psychological function. For example, movement can increase the detectability of visual traits (Fleishman, 1988; Endler \& Thery, 1996), and ornamental colours can amplify other colours without being the focus of female choice themselves (Brooks, 1996). This interaction between traits implies that multicomponent signals cannot be fully understood by investigating their components independently of one another.

Multicomponent signals can be multimodal, with components in several sensory modalities, or unimodal in just one modality. Multimodal signals enhance signal performance through intersensory facilitation, while unimodal multicomponent signals mainly improve the specificity of the information received along a single sensory channel, although the components can interact in a similar manner to those in bimodal compounds (Cohen, 1997; Aydin \& Pearce, 1997).

\section{(6) Multiple sensory environments}

When the ability to detect and assess different cues varies with environmental conditions or distances, individuals may pay attention to different cues under different conditions. This may facilitate mate assessment and increase the amount of information gained, reduce mate choice costs, or make mate assessment possible under different conditions. The different cues may convey the same information or, alternatively, have different functions. For example, some traits may increase detection at distance whereas others reflect quality at closer range. Lopez \& Martín (2001) found males of Iberian wall lizards, Podarcis hispanica, to pay attention to female coloration at long range, whereas odour cues seemed to be more important at close range. 
Several studies have found different cues to be used at different distances (Backwell \& Passmore, 1996; Gibson, 1996; Candolin \& Reynolds, 2001; Suk \& Choe, 2002) at different stages of the courtship ritual (Shine \& Mason, 2001; Luttbeg et al., 2001) or in different habitats or environments (Reynolds, 1993; Endler \& Houde, 1995). Most of the studies have found multiple cues to increase the amount of information gained (e.g. Candolin \& Reynolds, 2001) or to facilitate mate assessment under different conditions (Reynolds, 1993; Endler \& Houde, 1995). The cue that is most easily assessed at each distance, at each stage of the courtship ritual, or in each environment is usually emphasised. For example, Shine \& Mason (2001) found males of red-sided garter snakes, Thamnophis sirtalis parietalis, to use visual and thermal cues while searching for females, but pheromones increased in importance in the decision of whom to court after a mating ball had formed around a female.

\section{(7) Intersexual conflict and antagonistic coevolution}

The interests of the sexes often differ due to differences in potential reproductive rate (Bateman, 1948; Trivers, 1972). Males usually benefit from a high mating rate, whereas females, who usually have a lower potential reproductive rate, benefit from being more choosy. Males may then attempt to overcome female resistance to mate by evolving display traits that exploit pre-existing sensory biases. This induces females to mate in a suboptimal manner, which in turn selects them to evolve resistance to the display traits (Holland $\&$ Rice, 1998). Males may then be selected to evolve recurrently new display traits, which may result in them being adorned with multiple ornaments that are no longer useful in manipulation of female mating resistance but are needed as threshold traits before attention is given to other traits (Holland \& Rice, 1998).

Traits that are used for manipulating mating resistance should be continually evolving and would be expected to show large variation between closely related species (Parker \& Partridge, 1998; Arnqvist et al., 2000). So far there is no reliable evidence for multiple sexual cues evolving as a result of antagonistic coevolution. However, evidence exists for sexual conflict over mating rate (Rice, 1996; Arnqvist \& Danielsson, 1999; Pitnick, Brown \& Miller, 2001), for females evolving reduced attraction to traits that stimulate them to mate in a suboptimal manner (reviewed by Holland \& Rice, 1998), and for females showing no preference for some ornaments in highly ornamental bird species (Møller \& Pomiankowski, 1993; Ligon \& Zwartjes,
1995). Thus, it appears likely that sexual cues could evolve that increase male fitness at the expense of their mates, resulting in males with time becoming adorned with multiple uninformative, threshold cues. On the other hand, preferences that at first appear maladaptive, or to have no effect on fitness, might incur indirect benefits if the reproductive success of the offspring is enhanced due to the inheritance of the manipulating trait (Cordero \& Eberhard, 2003; Kokko et al., 2003). How common maladaptive and neutral preferences are is open to debate.

\section{THEORETICAL STUDIES ON THE EVOLUTION OF MULTIPLE GUES}

Although the use of multiple cues in mate choice was recognised already by Darwin (1871), the subject received little theoretical interest until one decade ago. An early model by Schluter \& Price (1993) indicated that female mating preferences for multiple sexual cues of male quality would only be stable if all cues were equally accurate indicators of condition, which is an unlikely circumstance. The model assumed that all cues were costly and that choice was costly in terms of direct search costs. When a wider range of cost functions for preferences was considered in models developed by Iwasa \& Pomiankowski, multiple preferences were found to be stable, but only if the overall cost of choice was not greatly increased by the use of additional cues in assessment (Pomiankowski \& Iwasa, 1993; Iwasa \& Pomiankowski, 1994). When the joint cost of multiple preferences increased, only a single preference was evolutionarily stable for handicap traits that indicated mate quality. However, weak preferences for multiple Fisherian traits could still evolve alongside a preference for a single dominant handicap trait. Later models by Johnstone (1995, 1996) suggested that multiple signals that indicate viability can be stable even when multiple mate preferences incur significant costs, provided that signalling costs are strongly accelerating.

Preferences for Fisherian runaway traits can lead to cyclic evolution with a continual evolutionary change in preferences and cues, if the joint cost of choice is large or the benefit small (Pomiankowski \& Iwasa, 1998). The Fisherian runaway process leads to semistable exaggeration of preferences for cues, followed by a slow decline in preferences due to the cost of choice. This eventually initiates a further runaway to a new semi-stable state, and this process is then repeated. With multiple preferences and cues, the number of exaggerated states increases greatly and results in a 
complex switching between different sexual phenotypes through evolutionary time. If populations differ in terms of natural selection, e.g. in predation risk, this process can result in divergence in mate preferences and mate choice cues between populations and promote speciation (Pomiankowski \& Iwasa, 1998).

A model by Holland \& Rice (1998) suggested that antagonistic coevolution between the sexes can accumulate costly male display traits that are no longer attractive to females but that are needed to achieve threshold levels of stimulation. Evolution of manipulating male display traits and counterselected female resistance to the same traits results in males being adorned with ornaments that have evolved at different times and differ in their importance in mate attraction. The model is motivated by three phenomena that are well documented: intersexual conflict with respect to mating, sensory exploitation, and female resistance to male traits and sensory stimulation (see Holland \& Rice, 1998).

Thus, theoretical models on the evolution of multiple cues and preferences suggest that preferences for multiple cues can evolve. The cues can be informative, uninformative or manipulating, whereas the preferences can be adaptive, maladaptive or have no effect on fitness. The models suggest that Fisherian attractiveness traits and uninformative traits that have arisen through the exploitation of sensory biases or antagonistic coevolution could be common and continually evolve and promote speciation under some circumstances.

Most of the models build on the critical assumption that the use of additional cues increases mate choice costs. This restricts the conditions when preferences for multiple cues can evolve. The possibility that the use of multiple cues reduces mate choice costs, and the consequences that this may have on the evolution of multiple cues and preferences have not been theoretically explored. However, several lines of research suggest that multiple cues can be used to reduce costs of choice (see below).

\section{WHAT DO MULTIPLE GUES INDICATE?}

Gues used in mate choice can either be informative cues that indicate direct or indirect fitness benefits to the receiver, or uninformative cues that facilitate mate choice, have no effect on receiver fitness, or even have a detrimental effect. Some comparative and empirical studies indicate that Fisherian attractiveness traits and uninformative cues are common and often occur alongside cues that indicate viability (see e.g. Møller
\&Pomiankowski, 1993;Omland, $1996 a, b ;$ Prum, 1997). The use of Fisherian cues is beneficial, as they indicate indirect fitness benefits to the female in terms of improved offspring fitness. Moreover, Fisherian cues can, under some conditions, be positively correlated with viability (Kokko et al., 2002). Whether the receiver gains fitness benefits from including uninformative cues in their mate choice decision is, however, mostly unknown. Preferences for uninformative cues can be beneficial if they facilitate mate choice. Alternatively preferences may have no effect on fitness, or even a detrimental effect, if they are remnants from past selection or are exploited by the signaller. The importance of receiver psychology and multiple sensory environments in favouring the evolution of multiple uninformative cues has received surprisingly little attention although these factors could be of major importance.

When it comes to informative indicator traits, several studies have found multiple signals to indicate direct material benefits to the female, such as male parental ability or territory quality (e.g. Price, 1984; Kraak, Bakker \& Mundwiler, 1999; Candolin \& Reynolds, 2001). Only a few studies, on the other hand, have investigated indirect, genetic benefits. For example, Dale \& Slagsvold (1996) found pied flycatcher (Ficedula hypoleuca) females to prefer males that were unmated, brightly coloured and had nest boxes with small entrance holes, all cues that indicated direct fitness benefits in the form of paternal care. However, genetic benefits might exist too, as plumage colour is in part heritable (Lundberg \& Alatalo, 1992; Slagsvold \& Lifjeld, 1992). In other species, where females base their mate choice on both male traits and territory characteristics, such as in sedge warblers (Acrocephalus schoenobanus) (Buchanan \& Catchpole, 1997), and great reed warblers (Acrocephalus arundinaceus) (Hasselquist et al., 1996), both direct and indirect benefits appear to occur; territory characteristics indicate expected reproductive success whereas male traits, such as song repertoire, probably indicate viability and genetic benefits.

The relative importance of direct and genetic benefits in driving the evolution of multiple indicator traits is unknown, as is the general importance of direct and genetic benefits in the evolution of single indicator traits. Genetic benefits are traditionally considered to be small (Møller \& Alatalo, 1999), and a recent metaanalysis suggested that the same may hold for direct benefits (Møller \& Jennions, 2001). When the mean weighted coefficients of determination gained in the meta-analyses were compared, direct benefits were found to be only slightly larger than genetic viability 
benefits, with the exception of hatching rate in mate guarding ectotherms.

In species, such as the guppy, where males offer no obvious resources to females, multiple signals most likely reflect genetic benefits. It is unclear whether they then reflect heritable viability, attractiveness or both. Indications of both have been found in the guppy as orange coloration, body size and display rate indicated viability in some populations (Houde, 1997), whereas a combination of multiple signals reflected attractiveness, but reduced viability, in another population (Brooks, 2000).

Preferences that are non-adaptive and do not increase fitness, or even are maladaptive and decrease fitness, have received little attention until the last few years. Antagonistic coevolution may be common (Rice, 1996; Holland \& Rice, 1998; Arnqvist \& Rowe, 2002), but how much it has contributed to the evolution of multiple cues and preferences remains to be determined. Similarly, exploitation of pre-existing sensory biases is well documented (Ryan \& Rand, 1993a; Endler \& Basolo, 1998), but whether this is adaptive or not to the receiver, by reducing mate choice costs or errors, is less known.

\section{INTERAGTION BETWEEN GUES}

Multiple cues may be assessed in an additive way, which means that the strength of preferences increases linearly with the number of concordant traits that are available to be assessed (Künzler \& Bakker, 2001). Another possibility is that an interaction occurs between traits, in which case the relationship between the strength of preferences and the number of cues used is more complex. This possibility has recently received increased attention and empirical evidence for it is growing.

Interactions may occur in several ways. First, the attention females pay to one cue may depend on the expression of another cue (Table 2). The two most common forms are multiplicative interactions and a sequential (hierarchical) use of cues. Evidence for a multiplicative interaction between cues has been found by Møller et al. (1998) for barn swallows (Hirundo rustica) where females paid more attention to song rate when assessing long-tailed attractive males than short-tailed unattractive males. Similarly, Kodric-Brown \& Nicoletto $(2001 b)$ found guppy females to pay differential attention to ornamental coloration and courtship behaviour depending on the relative expression of the two traits. Møller et al. (1998) suggested that flexible traits such as song and courtship activity may be less reliable indicators than fixed morphological traits because they show greater temporal variability and therefore are evaluated together with more reliable, fixed traits (see also Sullivan, 1994; Kokko et al., 1999). Another view was presented by Kodric-Brown \& Nicoletto $(2001 a)$ who argued that flexible, dynamic traits might better reflect current condition than fixed, static traits and therefore be of greater importance in female choice. The latter hypothesis might apply if males are paying a high cost for the fixed signals and for other reproductive activities and the flexible signals reflect the ability of individuals to cope with extra costs. Some support for this hypothesis has been gained in a metaanalysis of mating success among lekking species that found behavioural traits to be of greater importance than morphological traits in explaining female choice (Fiske, Rintamäki \& Karvonen, 1998). Nonetheless, both hypotheses suggest that interactions between traits should be common when traits differ in their reliability as signals of mate quality.

A sequential use of cues has been found in several studies, with one cue needing to exceed a threshold value before attention is paid to other cues (Table 2). For example, Borgia (1995) found bowerbird females (Chlamydera maculata) initially to be attracted to bones around the bowers that males built and decorated, whereas glass pieces close to the bower later stimulated females that entered the bowers to mate. Similarly, Gibson (1996) found female sage grouse (Centrocercus urophasianus) initially to be attracted to a subset of males based on acoustic components of the strut display, which is a long-range signal, but the probability that a visiting female mated was related to the male's display rate.

A related possibility is that a cue increases in importance when the variation among signallers in the expression of another cue is low or difficult to discriminate, or even inhibited. For example, in a wolf spider (Schizocosa ocreata) the visual display of foreleg tufts influences female choice only when vibrational communication is inhibited (Scheffer, Uetz \& Stratton, 1996). Vibrational communication is constrained in some populations by a complex leaf litter habitat. Alternatively, a trait may increase in importance when the messages transferred by other traits contradict each other, as has been found for the red jungle fowl (Gallus gallus) (Zuk, Ligon \& Thornhill, 1992).

A second category of interaction is when one cue amplifies the message of another and thereby facilitates female choice (Hasson, 1989, 1990, 1997). Due to certain features of receiver psychology, one cue may improve the perception and processing of another cue and improve the transmission of the message of the 
Table 2. Studies recording interaction among multiple cues in mate choice

\begin{tabular}{|c|c|c|c|}
\hline Category & Form of interaction & Sensory modes & References \\
\hline \multirow{23}{*}{$\begin{array}{l}\text { Attention paid to } \\
\text { one cue depends } \\
\text { on the expression } \\
\text { of another cue }\end{array}$} & \multicolumn{3}{|l|}{ Multiplicative interaction } \\
\hline & Drosophila melanogaster & Acoustic and chemical & Rybak, Sureau \& Aubin (2002) \\
\hline & Hirundo rustica & Visual and acoustic & Møller et al. (1998) \\
\hline & Poecilia reticulata & Visual & Kodric-Brown \& Nicoletto $(2001 b)$ \\
\hline & Taenopygia guttata & Visual and acoustic & Collins et al. (1994) \\
\hline & Tetrao tetrix & Visual & Höglund et al. (1994) \\
\hline & \multicolumn{3}{|l|}{ Sequential use of cues } \\
\hline & Centrocercus urophasianus & Visual and acoustic & Gibson (1996) \\
\hline & Chiroxiphia linearis & Visual and acoustic & McDonald (1989) \\
\hline & Chlamydera maculata & Visual & Borgia (1995) \\
\hline & Euplectes jacksoni & Visual & Andersson $(1989,1991)$ \\
\hline & Gryllus lineaticeps & Acoustic & Wagner \& Reiser (2000) \\
\hline & Rhodeus sericeus & Visual and chemical & Candolin \& Reynolds (2001) \\
\hline & Thamnophis sirtalis & $\begin{array}{l}\text { Visual, thermal and } \\
\text { chemical }\end{array}$ & Shine \& Mason (2001) \\
\hline & Uca annulipes & Visual & Backwell \& Passmore (1996) \\
\hline & \multicolumn{3}{|c|}{ Low variation in one cue increases the importance of other cues } \\
\hline & Ficedula hypoleuca & Visual & Dale \& Slagsvold (1996) \\
\hline & Passerculus sandwishensis princeps & Visual and acoustic & Reid \&Weatherhead (1990) \\
\hline & \multicolumn{3}{|c|}{ One cue increases in importance when other cues are inhibited or impossible to assess } \\
\hline & Malurus cyaneus & Visual & Green et al. (2000) \\
\hline & Schizocosa ocreata & Visual and vibrational & Scheffer et al. (1996) \\
\hline & \multicolumn{3}{|c|}{ One cue increases in importance when messages from other cues conflict } \\
\hline & Gallus gallus & Visual & Zuk et al. (1992) \\
\hline \multirow[t]{5}{*}{ Amplifiers } & \multicolumn{3}{|c|}{ One cue amplifies or improves reception of another cue } \\
\hline & Gasterosteus aculeatus & Visual & $\begin{array}{l}\text { McLennan \& McPhail (1990), } \\
\text { Brønseth \& Folstad (1997) }\end{array}$ \\
\hline & Plexippus paykulli & Visual & Taylor, Hasson \& Clark (2000) \\
\hline & Poecilia reticulata & Visual & Brooks (1996) \\
\hline & Schizocosa spp. & Visual & Hebets \& Uetz (2000) \\
\hline \multirow{3}{*}{$\begin{array}{l}\text { One cue influences the } \\
\text { cost of another cue }\end{array}$} & \multicolumn{3}{|c|}{ One cue influences the cost and expression of another cue } \\
\hline & Poecilia reticulata & Visual & Reynolds (1993) \\
\hline & Trochilus polytmus & Visual & Evans et al. (1994) \\
\hline
\end{tabular}

signal. In particular, courtship displays may expose and amplify ornamental traits. In the threespine stickleback (Gasterosteus aculeatus) for example, zig-zag movements during courtship expose the male's red ventral coloration to the female (McLennan \& McPhail, 1990). Other examples are tail markings of birds that amplify tail length, shape or feather quality (Hasson, 1991; Fitzpatrick, 1998), and ornaments that amplify other ornamental traits, such as in guppies where black colours enhance areas of orange (Brooks, 1996).

A third category of interaction is when a cue influences the cost and expression of another cue (Johnstone, 1996). For example, an asymmetric tail can increase the cost of tail elongation, which can prevent low-quality males from developing long tails (Evans, 1993; Evans \& Hatchwell, 1993; Evans, Martins \& Haley, 1994). Similarly, a large body size, which is often used as a cue in mate choice, can make an individual conspicuous to predators and increase predation risk during courtship, as found for guppies (Reynolds, 1993). Furthermore, if the interaction between traits depends on environmental conditions, then the expression of the traits too depends on the environment. This has been demonstrated in the guppy where an increase in light level and, thus, perceived predation risk reversed a trend of attractive, large males courting more often than small males (Reynolds, 1993). 


\section{EVOLUTION OF MULTIPLE PREFERENGES AND GUES}

Several different factors may favour the evolution of preferences for multiple cues, as detailed above. A single preference may select for multiple cues, or each cue may coevolve with a different preference, as demonstrated for guppies (Brooks \& Couldridge, 1999). The cues may evolve together and be functionally linked, as has been found for display morphology and behaviour of birds (Prum, 1990) and fish (McLennan, 1991, 1996). Alternatively, their evolution may be decoupled so that traits evolve independently of each other, as has been found for visual and olfactory cues of pupfish (Strecker \& Kodric-Brown, 1999; KodricBrown \& Strecker, 2001), for display morphology and behaviour of lizards (Wiens, 2000) and for beak size and vocalisations of Darwin's finches (Grant, Grant \& Petren, 2000).

\section{(1) When do females use multiple cues?}

A factor that should have a profound influence on the use of multiple cues is the cost of being choosy in terms of costs of searching for mates and costs of assessing their traits. Most theoretical models assume that the use of multiple cues increases mate-choice costs, while it decreases mate-choice errors (e.g. Pomiankowski \& Iwasa, 1993; Iwasa \& Pomiankowski, 1994; Johnstone, 1995, 1996). Although this may not always hold, as will be discussed later, it has led to the suggestion that multiple cues may be common in species where the cost of choice is low or where females benefit significantly from evaluating several cues, i.e. in lekking species where females can evaluate several males at one time, and in social species where males and females spend time together outside the breeding season and the cost of mate choice may therefore be low (Møller \& Pomiankowski, 1993). From the signallers point of view, the cost of expressing several display traits should not be too high in relation to mating benefits to the signaller. This suggests that multiple displays should be most common in polygynous species with a high intensity of sexual selection and, thus, large potential benefits of displaying (Møller \& Pomiankowski, 1993).

Surprisingly few comparative analyses have examined interspecific variation in the number of male display traits in relation to mating system and ecological factors, and all of them are on birds. Two studies suggest that polygamous species, and especially lekking species, have more display traits than monogamous species and that the traits are probably Fisherian attractiveness traits (Møller \& Pomiankowski, 1993; Prum, 1997). However, ecological factors can influence the evolution of multiple displays, such as in dabbling ducks where males displaying on land have a reduced repertoire size compared to species displaying on water, probably due to increased risk of predation on land (Johnson, 2000). An interesting pattern has been found in peacock pheasants (Polyplectron spp.) where habitat differences appear to have contributed to the loss of multiple cues in recently evolved montane species compared to older species in lowland regions (Kimball et al., 2001). More studies, particularly on species other than birds, are now needed to determine the generality of these findings on the relationship between multiple cues and mating system and ecology.

\section{(2) Increased or decreased costs of choice?}

The assumption that the use of multiple cues increases mate choice costs may hold if it increases energy expenditure or the time that a female spends inspecting males, which could result in lost mating opportunities, less time available for foraging or increased risk of predation. Moreover, the capacity to assess and remember several traits may require increased brain size or larger sensory organs, which may be costly. However, a few recent studies indicate that the use of multiple cues can reduce mate choice costs. When multiple cues are used sequentially, a first cue may indicate which males are worth inspecting for a second cue that is more costly to evaluate than the first but gives more information about mate quality. This occurs in the fiddler $\operatorname{crab}(U c a$ annulipes) where females first decide which males to sample based on male size (Backwell \& Passmore, 1996). They then decide whether or not to mate with a male based on features of the burrow that he is defending. Similarly, in a freshwater fish, the European bitterling (Rhodeus sericeus), where males attract females to spawn in living mussels, females base their initial decision of whether to inspect a mussel on the coloration and courtship behaviour of the male, whereas the final spawning decision is based on the quality of the mussel, which influences survival of the offspring (Candolin \& Reynolds, 2001). This reduces the number of males that are inspected more closely and, thus, mate-sampling costs. Several other studies have found different cues to be used at different stages of the courtship ritual (Andersson, 1989, 1991; McDonald, 1989; Borgia, 1995; Gibson, 1996; Shine \& Mason, 2001; Luttbeg et al., 2001), which suggests that sequential use of cues could be common. 
Another possibility is that multiple cues facilitate choice by allowing females to base their mate choice on the trait (quality) that shows the largest difference among males. A study on pied flycatchers showed that of three different traits that were used as cues in female choice, the trait that showed the largest difference among males was used as the decisive cue, although the comparison was based on difference values that differed in dimension (metric and categorical variables) and were not scaled to the mean (Dale \& Slagsvold, 1996). The use of multiple cues could reduce mate choice costs by reducing the time spent inspecting mates, as mate choice generally takes longer the more equal mates are (Real, 1990; Reynolds \& Gross, 1990). A quick assessment of several cues might allow females to detect quickly a difference between males, whereas the assessment of only one cue might prolong the time required for detection. Similarly, amplifying traits may reduce mate choice costs by decreasing the time needed to estimate mate quality accurately. Moreover, the use of different sensory modalities to assess mate quality, such as vision and sound, may increase the amount of information gained and decrease the time or energy spent on mate assessment.

Thus, contrary to the common expectation of multiple cues being favoured in species where mate choice incurs low costs, multiple cues might just as easily evolve in species where mate choice incurs high costs, as a means to reduce these costs.

\section{CONSEQUENGES OF THE USE OF MULTIPLE GUES}

The use of multiple cues may have profound influences on the strength of sexual selection and, thus, on the maintenance of variation. Moreover, it could result in the evolution of alternative signalling tactics and promote speciation.

\section{(1) Strength of sexual selection and the maintenance of variation}

Mate choice based on multiple cues could increase the strength of selection if it skews mate choice against particular mates, for example by facilitating mate assessment and reducing mate choice errors. On the other hand, the strength of selection may decrease if individuals vary in their mate preferences or choosiness, if different signals are assessed under different environmental conditions or environmental conditions determine signal interaction and expression, or if the signal traits are genetically correlated and indirect selection counteracts direct selection. The question of whether the use of multiple cues increases or decreases the intensity of sexual selection has so far received little theoretical and empirical attention. However, the frequent findings that multiple cues are not strongly correlated and that large variation in female preferences exists suggest that the use of multiple cues may often decrease the strength of selection. On the other hand, their predominance in lekking species, where mating success is often highly skewed, suggests the opposite.

Significant variation among females in their preference functions and choosiness has been demonstrated in several studies (Jennions \& Petrie, 1997; Widemo \& Saether, 1999; Murphy \& Gerhardt, 2000), although only a few have demonstrated that this variation is adaptive (reviewed by Widemo \& Saether, 1999). The effect that variation in mate choice behaviour could have on the strength of sexual selection has, however, received less empirical attention. Recently, Brooks \& Endler (2001 b) demonstrated that in guppies there is no universally attractive male phenotype, as females vary in their preferences for some cues. This variation in preferences and choosiness was found to influence the intensity of selection on some traits, although not on others. Variation in preferences could therefore contribute to the maintenance of variation in sexual traits. More studies on a variety of species are now needed to determine the generality of this finding.

Another unexplored possibility is that the occurrence of multiple cues results in temporal variation in phenotypic preferences. If higher weighting is always given to the cue that shows the largest variation, then this cue will be emphasised in mate choice until the variation is reduced and other cues increase in importance. Moreover, variation in preferences could lead to frequency-dependent selection if such variation has a genetic component (Partridge \& Hill, 1984).

Regarding an effect of temporal and spatial environmental variation on signal assessment, several studies on single traits have demonstrated an influence of factors such as predation risk (Magnhagen, 1991), social environment (Greenfield, 1994) and signal detectability (Wiley, 1994) on mate preferences or choosiness. However, whether females weight multiple traits differently depending on environmental conditions and thereby cause spatial and temporal variation in selection pressures has received less attention. Some evidence exists for Ipswich sparrows (Passerculus sandwishensis princeps), as the relative importance of two cues, territory size and song rate, has been found to differ between years (Reid \& Weatherhead, 1990). Similarly, mate choice criteria of guppies show geographic variation with the intensity, sign and number of cues used 
varying among localities (Endler \& Houde, 1995). When it comes to an effect of environmental variation on the expression of cues the same pattern emerges. Many studies have demonstrated an effect of environmental factors, such as predation risk, on the expression of single traits (e.g. Endler, 1982; Hedrick, 2000), whereas only a few have presented evidence for an effect of environmental variation on the relative expression of multiple traits and their interaction (Reynolds, 1993; Endler, 1995; Basolo, 1998).

The possibility that indirect selection, through direct selection on a genetically correlated cue, influences the strength of selection by preventing simultaneous optimisation of all cues has received surprisingly little theoretical and empirical attention. A recent study on guppies showed that indirect selection can weaken or oppose the elaboration of a trait, which suggests that indirect selection and antagonistic pleiotropy can have large effects on overall selection (Brooks \& Endler, $2001 a$ ). This can occur when cues are not strongly positively correlated, which includes cues that reflect different aspects of mate quality, or cues that have arisen independently through Fisher's runaway process or through sensory exploitation. On the other hand, the importance of antagonistic pleiotropy in maintaining polymorphism has been questioned (Hedrick, 1999), which calls for more studies.

A reduction in the strength of selection due to the use of multiple cues could contribute to the maintenance of genetic variation. Strong directional selection is expected to erode additive genetic variation in sexual traits, giving rise to the lek paradox (Kirkpatrick \& Ryan, 1991). The importance that the use of multiple cues could play in the maintenance of variation should prove a rewarding area for future studies.

\section{(2) Speciation and the evolution of alternative signalling tactics}

Multiple cues may promote speciation if the relative importance of different cues diverges within a population and this leads to assortative mating. A model by Schluter \& Price (1993) indicated that preferences for multiple traits can diverge between isolated populations and lead to speciation if environmental differences affect the detectability of the traits or the intensity of natural selection against the traits (i.e. the costs of the traits). For example, visual cues could be easier to assess or pose less predation risk in one habitat, whereas acoustic cues could do better in another habitat. Another possibility is that female preferences diverge in arbitrary directions if different traits yield equivalent benefits. In particular, sexual traits that have evolved through Fisher's runaway process and do not have a strong link with quality can easily diverge in allopatry (Pomiankowski \& Iwasa, 1998). Traits that have arisen through the exploitation of sensory biases in the females, on the other hand, are less likely to lead directly to speciation, as females would interbreed with both male populations unless female sensory biases also changed (Panhuis et al., 2001). Support for the importance of multiple cues in speciation by sexual selection has been gained in the Vogelkop bowerbird (Amblyornis inornatus) where newly diverged populations differed in a suite of display traits and female preferences ( $\mathbf{U y} \&$ Borgia, 2000). Similarly, variation in preferences and ornamentation appears to occur among populations of pied flycatchers: the white forehead patch is sexually selected in some populations but not in others, where plumage colour instead appears to be of importance (Dale et al., 1999).

The importance of sexual selection in sympatric speciation, on the other hand, is disputed, and conclusive evidence is lacking (Turelli, Barton \& Coyne, 2001). A good candidate is the rapid divergence of cichlids in the African Great Lakes where species differ in coloration and female choice for male coloration appears to have been important in speciation (Seehausen, Alphen \& Witte, 1997; Seehausen \& Alphen, 1998; Galis \& Metz, 1998; Wilson, 2000). Similarly, in a recently evolved group of Mexican pupfish (Cyprinodon spp.) variation occurs among sympatric morphospecies in the importance of visual and chemical cues in mate recognition (Strecker \& Kodric-Brown, 1999, 2000; Kodric-Brown \& Strecker, 2001).

The use of multiple cues has been proposed to have the potential to result in the evolution of alternative signalling tactics within species, if different signals reflect different qualities. Males that excel in one quality may employ one kind of signal, whereas those that excel in another quality may employ another kind, as suggested by Johnstone (1996). Potential examples are species where males adopt alternative reproductive tactics. Males that become territorial, nesting males may advertise their quality as a social mate by using signals that reflect direct benefits, such as parental care, whereas non-nesting males could advertise their quality as extra-pair mates by employing signals of genetic quality.

\section{CONGLUSIONS AND DIREGTIONS FOR FUTURE RESEARGH}

(1) Evidence for the use of multiple cues in mate choice has been steadily increasing during the last 
decade. Multiple cues occur in most mating systems and can be beneficial indicator traits, uninformative traits that facilitate mate choice or have no effect on fitness, or manipulative cues that decrease receiver fitness. A few recent studies suggest that most multiple cues are Fisherian cues or uninformative cues that occur alongside a viability indicator and facilitate detection, improve signal reception or are remnants from past selection pressures [see Jennions, Møller \& Petrie (2001), Møller \& Alatalo (1999) for support for single traits indicating mate quality]. How common neutral or maladaptive preferences are is unknown, but recent studies on sexual conflict suggest that manipulating cues could be more common than previously believed (Holland \& Rice, 1998). On the other hand, an increasing number of studies present evidence for multiple cues indicating quality. Most of these find multiple cues to be used as multiple messages that reflect different aspects of mate quality. Back-up signals appear to be less common.

(2) Mating system and ecological factors can influence the number of cues used and probably the relative occurrence of unreliable and indicator traits. However, more comparative studies are needed on a wider array of species before any firm conclusion can be drawn on the function of multiple cues and the influencing factors.

(3) Factors that may promote the evolution of multiple cues, but which have received surprisingly little attention in the contemporary literature, are multiple sensory environments and receiver psychology. Cues often vary in the ease with which they can be assessed at different distances, at different stages of the courtship ritual, or in different habitats or environments. Adjusting the attention paid to different cues according to environmental conditions or distances could facilitate female choice or reduce errors. Moreover, many signals consist of several components, which can enhance detection, recognition, discrimination or memorability of the signal, due to receiver psychology.

(4) Another topic that has been little studied, but which is of crucial importance in mate choice, is the interaction among multiple cues. Several lines of evidence suggest that interaction among cues is a common phenomenon and can influence mate choice or facilitate assessment. More attention should be paid to signal interaction in future studies.

(5) Multiple cues have generally been assumed to increase the cost of mate choice, which would constrain the evolution of multiple cues. In opposition to this expectation, several recent lines of evidence suggest that the use of multiple cues decreases the cost by decreasing the number of mates inspected more closely (at high cost) or the time and energy spent inspecting a set of mates. A reduction in the cost of choice should promote the evolution of preferences for multiple cues, including cues that do not indicate large fitness benefits. This might be a general explanation for why multiple cues are so common, which has been an intriguing question in studies of sexual selection. Multiple cues, and especially multiple indicator cues, are not expected to be common based on models that assume costs of mate choice to increase with the number of cues used.

(6) The consequences that the use of multiple cues may have for sexual selection and speciation have received surprisingly little attention but should prove a rewarding area for future studies. A few recent studies suggest that multiple cues may play a role in the maintenance of genetic variation and in speciation by sexual selection, both of which are currently debated topics.

(7) The number of studies on the use of multiple cues will surely continue to increase in the near future, as it is increasingly realised that mate choice is based on several, often interacting, cues and not on only one decisive cue. More studies are needed on the factors that promote the evolution of multiple cues, especially the cost of mate choice, receiver psychology, ecological factors and individual variation in preferences. Another rewarding area for future studies is the consequences that the use of multiple cues may have at the individual and the species level.

\section{AGKNOWLEDGEMENTS}

I thank Martin Brinkhof, Hanna Kokko, John Reynolds, Franziska Schädelin, Hannes Scheuber and anonymous referees for inspiring discussions and valuable comments on the manuscript. The study was supported by the Academy of Finland.

\section{REFERENGES}

Alatalo, R. V., Lundberg, A. \& Glynn, C. (1986). Female pied flycatchers choose territory quality and not male characteristics. Nature 323, 152-153.

Andersson, M. (1994). Sexual Selection. Princeton University Press, Princeton.

Andersson, S. (1989). Sexual selection and cues for female choice in leks of Jackson widowbird, Euplectes jacksoni. Behavioral Ecology and Sociobiology 25, 403-410.

Andersson, S. (1991). Bowers of the savanna-display courts and mate choice in a lekking widowbird. Behavioral Ecology 2, 210-218. 
Arnqvist, G. \& Danielsson, I. (1999). Copulatory behavior, genital morphology, and male fertilization success in water striders. Evolution 53, 147-156.

Arnqvist, G., Edvardsson, M., Friberg, U. \& Nilsson, T. (2000). Sexual conflict promotes speciation in insects. Proceedings of the National Academy of Sciences U.S.A. 97, 10460-10464.

Arnqvist, G. \& Rowe, L. (2002). Antagonistic coevolution between the sexes in a group of insects. Nature 415, 787-789.

Aydin, A. \& Pearce, J. M. (1997). Some determinants of response summation. Animal Learning \& Behavior 25, 108-121.

Backwell, P. R. Y., Christy, J. H., Telford, S. R., Jennions, M. D. \& Passmore, N. I. (2000). Dishonest signalling in a fiddler crab. Proceedings of the Royal Society of London Series B 267, 719-724.

Backwell, P. Y. \& Passmore, N. I. (1996). Time constraints and multiple choice criteria in the sampling behaviour and mate choice of the fiddler crab, Uca annulipes. Behavioral Ecology and Sociobiology 38, 407-416.

Badyaev, A. V., Etges, W. J., Faust, J. D. \& Martin, T. E. (1998). Fitness correlates of spur length and spur asymmetry in male wild turkeys. Fournal of Animal Ecology 67, 845-852.

Badyaev, A. V., Hill, G. E., Dunn, P. O. \& Glen, J. G. (2001). Plumage color as a composite trait: developmental and functional integration of sexual ornamentation. American Naturalist 158, 221-235.

Balmford, A., Rosser, A. M. \& Albon, S. D. (1992). Correlates of female choice in resource-defending antelope. Behavioral Ecology and Sociobiology 31, 107-114.

BART, J. \& EARnst, S. L. (1999). Relative importance of male and territory quality in pairing success of male rock ptarmigan (Lagopus mutus). Behavioral Ecology and Sociobiology 45, 355-359.

Basolo, A. (1998). Shift in investment between sexually selected traits: tarnishing of the silver spoon. Animal Behaviour 55, 665-671.

Bateman, A. J. (1948). Intra-sexual selection in Drosophila. Heredity 2, 349-368.

Bennett, P. M. \& Owens, I. P. F. (2002). Evolutionary Ecology of Birds. Oxford University Press, Oxford.

Birkhead, T. R., Fletcher, F. \& Pellatt, E. J. (1998). Sexual selection in the zebra finch Taeniopygia guttata: condition, sex traits and immune capacity. Behavioral Ecology and Sociobiology 44, 179-191.

Boake, C. R., De Angelis, M. P. \& Andreadis, D. K. (1997). Is sexual selection and species recognition a continuum? Mating behaviour of the stalk-eyed fly Drosophila heteroneura. Proceedings of the National Academy of Science U.S.A. 94, 12442-12445.

Borgia, G. (1995). Complex mate displays and female choice in the spotted bowerbird: specialized functions for different bower decorations. Animal Behaviour 49, 1291-1301.

Brønseth, T. \& Folstad, I. (1997). The effect of parasites on courtship dance in threespine sticklebacks: more than meets the eye? Canadian Fournal of Zoology 75, 589-594.

BRoOKs, R. (1996). Melanin pigment as a visual signal amplifier in male guppies. Naturwissenschaften 83, 39-41.

Brooks, R. (2000). Negative genetic correlation between male sexual attractiveness and survival. Nature 406, 67-70.

Brooks, R. \& Couldridge, V. (1999). Multiple sexual ornaments coevolve with multiple mating preferences. American Naturalist 154, 37-45.

Brooks, R. \& Endler, J. A. (2001a). Direct and indirect sexual selection and quantitative genetics of male traits in guppies (Poecilia reticulata). Evolution 55, 1002-1015.
Brooks, R. \& Endler, J. A. (2001 b). Female guppies agree to differ: phenotypic variation in mate-choice behavior and the consequence for sexual selection. Evolution 55, 1644-1655.

Buchanan, K. L. \& Catchpole, C. K. (1997). Female choice in the sedge warbler, Acrocephalus schoenobaenus: multiple cues from song and territory quality. Proceedings of the Royal Society of London Series $B$ 264, 521-526.

Burley, N. (1986). Sexual selection for aesthetic traits in species with biparental care. American Naturalist 127, 415-445.

Candolin, U. (1999). The relationship between signal quality and physical condition: is sexual signalling honest in the three-spined stickleback? Animal Behaviour 58, 1261-1267.

Candolin, U. (2000). Changes in expression and honesty of sexual signalling over the reproductive lifetime of sticklebacks. Proceedings of the Royal Society of London Series B 267, 2425-2430.

Candolin, U. \& Reynolds, J. D. (2001). Sexual signaling in the European bitterling: females learn the truth by direct inspection of the resource. Behavioral Ecology 12, 407-411.

Candolin, U. \& Voigt, H.-R. (2001). Correlation between male size and territory quality: consequence of male competition or predation risk? Oikos 95, 225-230.

Carranza, J. (1995). Female attraction by males versus sites in territorial rutting red deer. Animal Behaviour 50, 445-453.

Cohen, D.J. (1997). Visual detection and perceptual independence: assessing color and form. Perception \& Psychophysics 59, 623-635.

Coldins, S. A., Hubbard, C. \& Houtman, A. M. (1994). Female mate choice in the zebra finch - the effect of male beak color and male song. Behavioral Ecology and Sociobiology 35, 21-25.

Cordero, G. \& Eberhard, W. G. (2003). Female choice of sexually antagonistic male adaptations: a critical review of some current research. Fournal of Evolutionary Biology 16, 1-6.

Crapon de Caprona, M. D. C. \& Ryan, M. J. (1990). Conspecific mate recognition in swordtails, Xiphohorus nigrensis and $X$. pygmaeus (Poecilidae) - olfactory and visual cues. Animal Behaviour 39, 290-296.

Dale, S. \& Slagsvold, T. (1996). Mate choice on multiple cues, decision rules and sampling strategies in female pied flycatchers. Behaviour 133, 903-944.

Dale, S., Slagsvold, T., Lampe, H. M. \& Saetre, G. P. (1999). Population divergence in sexual ornaments: the white forehead patch of Norwegian pied flycatchers is small and unsexy. Evolution 53, 1235-1246.

Darwin, C. (1871). The Descent of Man, and Selection in Relation to Sex. Murray, London.

Dawkins, M. S. \& Guilford, T. (1991). The corruption of honest signalling. Animal Behaviour 41, 865-873.

ENDLER, J. A. (1982). Convergent and divergent effects of natural selection on colour patterns in two fish faunas. Evolution $\mathbf{3 6}$, 178-188.

ENDLER, J. A. (1995). Multiple-trait coevolution and environmental gradients in guppies. Trends in Ecology and Evolution 10, 22-29.

Endler, J. A. \& Basolo, A. L. (1998). Sensory ecology, receiver biases and sexual selection. Trends In Ecology and Evolution 13, 415-420.

Endler, J. A. \& Houde, A. E. (1995). Geographic variation in female preferences for male traits in Poecilia-reticulata. Evolution 49, 456-468.

EndLer, J. A. \& Thery, M. (1996). Interacting effects of lek placement, display behavior, ambient light, and color patterns in three neotropical forest-dwelling birds. American Naturalist 148, 421-452. 
Eshel, I., Volovik, I. \& Sansone, E. (2000). On Fisher-Zahavi's handicapped sexy son. Evolutionary Ecology Research 2, 509-523.

Evans, M. R. (1993). Fluctuating asymmetry and long tails: the mechanical effects of asymmetry may act to enforce honest advertisement. Proceedings of the Royal Society of London Series B 253, 205-209.

Evans, M. R. \& Hatchwell, B. J. (1993). New slants on ornament asymmetry. Proceedings of the Royal Society of London Series B 251, $171-177$.

Evans, M. R., Martins, T. L. F. \& Haley, M. (1994). The asymmetrical cost of tail elongation in red-billed streamertails. Proceedings of the Royal Society of London Series B 256, 97-103.

Fisher, R. A. (1930). The Genetical Theory of Natural Selection. Clarendon Press, Oxford.

Fiske, P., Rintamäki, P. T. \& Karvonen, E. (1998). Mating successs in lekking males: a meta analysis. Behavioral Ecology 9, 328-338.

Fitze, P. S. \& Richner, H. (2002). Differential effects of a parasite on ornamental structures based on melanins and carotenoids. Behavioral Ecology 13, 401-407.

FitzPATRICK, S. (1998). Birds' tails as signaling devices: markings, shape, length, and feather quality. American Naturalist 151 157-173.

Fleishman, L. J. (1988). Sensory influences on physical design of a visual display. Animal Behaviour 36, 1420-1424.

Fox, D. L. (1976). Animal Biochromes and Structural Colours. University of California Press, Berkeley, CA.

Galis, F. \& Metz, A.J. (1998). Why are there so many cichlid species? Trends In Ecology and Evolution 13, 1-2.

Gerhardt, H. C. (1982). Sound pattern-recognition in some North-American treefrogs (Anura, Hylidae) - implications for mate choice. American Zoologist 22, 581-595.

Gerhardt, H. C. (2001). Acoustic communication in two groups of closely related treefrogs. Advances in the Study of Behavior 30 , 99-167.

Getty, T. (1999). Chase-away sexual selection as noisy reliable signaling. Evolution 53, 299-302.

Gibson, R. M. (1996). Females choice in sage grouse: the roles of attraction and active comparison. Behavioral Ecology and Sociobiology 39, 55-59.

Goodwin, T. W. (1984). The Biochemistry of the Carotenoids. Chapman \& Hall, London.

Goulet, D. (1998). Spawning success in the damselfish, Amblyglyphidodon leucogaster: the influence of eggs in the nest. Animal Behaviour 55, 651-664.

Grant, P. R., Grant, B. R. \& Petren, K. (2000). The allopatric phase of speciation: the sharp-beaked ground finch (Geospiza difficilis) on the Galapagos islands. Biological Fournal of the Linnean Society 69, 287-317.

Green, D.J., Osmond, H. L., Double, M. C. \& Cockburn, A. (2000). Display rate by male fairy wrens (Malurus cyaneus) during the fertile period of females has little influence on extra-pair mate choice. Behavioral Ecology and Sociobiology 48, 438-446.

GreEN, D. M. (1964). Detection of multicomponent signals in noise. In Signal Detection and Recognition by Human Observers (ed. J. A. Swets), pp. 491-507. J. Wiley, New York.

Greenfield, M. D. (1994). Cooperation and conflict in the evolution of signal interactions. Annual Reviewes of Ecology and Systematics 25, 97-126.

Guilford, T. \& Dawkins, M. S. (1991). Receiver psychology and the evolution of animal signals. Animal Behaviour 42, 1-14.

Guilford, T. \& Dawkins, M. S. (1993). Receiver psychology and the design of animal signals. Trends in Neurosciences 16, 430-436.
Hankinson, S. J. \& Morris, M. R. (2002). Sexual selection and species recognition in the pygmy swordtail, Xiphophorus pygmaeus: conflicting preferences. Behavioral Ecology and Sociobiology 51, $140-145$

Hasselquist, D., Bensch, S. \& von Schantz, T. (1996). Correlation between male song repertoire, extra-pair paternity and offspring survival in the great reed warbler. Nature 381, 229-232.

Hasson, O. (1989). Amplifiers and the handicap principle in sexual selection: a different emphasis. Proceedings of the Royal Society of London Series B 235, 383-406.

Hasson, O. (1990). The role of amplifiers in sexual selection - an integration of the amplifying and the fisherian mechanisms. Evolutionary Ecology 4, 277-289.

Hasson, O. (1991). Sexual displays as amplifiers - practical examples with an emphasis on feather decorations. Behavioral Ecology 2, 189-197.

Hasson, O. (1997). Towards a general theory of biological signaling. Fournal of Theoretical Biology 185, 139-156.

Hebets, E. A. \& Uetz, G. W. (2000). Leg ornamentation and the efficacy of courtship display in four species of wolf spider (Araneae: Lycosidae). Behavioral Ecology and Sociobiology 47, 280-286.

Hedrick, A. V. (2000). Crickets with extravagant mating songs compensate for predation risk with extra caution. Proceedings of the Royal Society of London Series B 267, 671-675.

Hedrick, P. W. (1999). Antagonistic pleiotropy and genetic polymorphism: a perspective. Heredity 82, 126-133.

Hill, G. E. \& Montgomerie, R. (1994). Plumage colour signals nutritional condition in the house finch. Proceedings of the Royal Society of London Series B 258, 47-52.

Hill, J.-A., Enstrom, D. A., Ketterson, E. D., van Nolan, JR. \& Ziegenfus, C. (1999). Mate choice based on static versus dynamic secondary sexual traits in the dark-eyed junco. Behavioral Ecology 10, 91-96.

Hoelzer, G. A. (1989). The good parent process of sexual selection. Animal Behaviour 38, 1067-1078.

Höglund, J., Alatalo, R. V., Lundberg, A. \& Ratti, O. (1994). Context-dependent effects of tail ornament damage on mating success in black grouse. Behavioral Ecology 5, 182-187.

Holland, B. \& Rice, W. R. (1998). Perspective: chase-away sexual selection: antagonistic seduction versus resistance. Evolution 52, $1-7$.

Houde, A. E. (1997). Sex, Color, and Mate Choice in Guppies. Princeton University Press, Princeton, NJ.

Houtman, A. M. (1992). Female zebra finches choose extra-pair copulations with genetically attractive males. Proceedings of the Royal Society of London Series B 249, 3-6.

Hultsch, H., Schleuss, F. \& TodT, D. (1999). Auditory-visual stimulus airing enhances perceptual learning in a songbird. Animal Behaviour 58, 143-149.

Iwasa, Y. \& Pomiankowski, A. (1994). The evolution of mate preferences for multiple sexual ornaments. Evolution 48, 853-867.

Jennions, M. D., Møller, A. P. \& Petrie, M. (2001). Sexually selected traits and adult survival: a meta-analysis Quarterly Review of Biology 76, 3-36.

Jennions, M. D. \& Petrie, M. (1997). Variation in mate choice and mating preferences: a review of causes and consequences. Biological Review 72, 283-327.

Johnson, K. P. (2000). The evolution of courtship displays repertoire size in the dabbling ducks (Anatini). Fournal of Evolutionary Biology 13, 634-644. 
Johnstone, R. A. (1994). Honest signalling, perceptual error and the evolution of 'all-or-nothing' displays. Proceedings of the Royal Society of London Series B 256, 169-175.

Johnstone, R. A. (1995). Honest advertisement of multiple qualities using multiple signals. Fournal of Theoretical Biology 177, 87-94.

Johnstone, R. A. (1996). Multiple displays in animal communication: 'backup signals' and 'multiple messages'. Philosophical Transactions of the Royal Society of London Series B 351, 329-338.

Johnstone, R. A. (1997). The evolution of animal signals. In Behavioural Ecology. An Evolutionary Approach (ed. J. R. Krebs and N. B. Davies), pp. 155-178. Blackwell Science, Oxford.

Johnstone, R. A. \& Grafen, A. (1993). Dishonesty and the handicap principle. Animal Behaviour 46, 759-764.

Kimball, R. T., Braun, E. L., Ligon, J. D., Lucchini, V. \& Randi, E. (2001). A molecular phylogeny of the peacock-pheasants (Galliformes: Polyplectron spp.) indicates loss and reduction of ornamental traits and display behaviours. Biological Fournal of the Linnean Society 73, 187-198.

Kirkpatrick, M. \& Ryan, M.J. (1991). The evolution of mating preferences and the paradox of the lek. Nature 350, 33-38.

Kodric-Brown, A. (1993). Female choice of multiple male criteria in guppies: interacting effects of dominance, coloration and courtship. Behavioral Ecology and Sociobiology 32, 415-420.

Kodric-Brown, A. \& Nicoletto, P. F. (2001 a). Age and experience affect female choice in the guppy (Poecilia reticulata). American Naturalist 157, 316-323.

Kodric-Brown, A. \& Nicoletto, P. F. (2001 b). Female choice in the guppy (Poecilia reticulata): the interaction between male color and display. Behavioral Ecology and Sociobiology 50, 346-351.

Kodric-Brown, A. \& Strecker, U. (2001). Responses of Cyprinodon maya and C-labiosus females to visual and olfactory cues of conspecific and heterospecific males. Biological Fournal of the Linnean Society 74, 541-548.

Kokko, H. (1998). Should advertising parental care be honest? Proceedings of the Royal Society of London Series B 265, 1871-1878.

Kokko, H., Rintamäki, P. T., Alatalo, R. V., Höglund, J., Karvonen, E. \& LundBerg, A. (1999). Female choice selects for lifetime lekking performance in black grouse males. Proceedings of the Royal Society of London Series B 266, 2109-2115.

Kokko, H., Brooks, R., Jennions, M. \& Morley, J. (2003). The evolution of mate choice and mating biases. Proceedings of the Royal Society of London Series $B$, in press.

Kokko, H., Brooks, R., McNamara, J. M. \& Houston, A. I. (2002). The sexual selection continuum. Proceedings of the Royal Society of London Series B 269, 1331-1340.

KraAk, S. B. M., Bakker, T. C. M. \& Mundwiler, B. (1999). Sexual selection in sticklebacks in the field: correlates of reproductive, mating, and paternal success. Behavioral Ecology 10, 696-706.

KünZleR, R. \& BAKkeR, T. C. M. (2001). Female preferences for single and combined traits in computer animated stickleback males. Behavioral Ecology 12, 681-685.

Kvarnemo, C. (1995). Size-assortative nest choice in the absence of competition in males of the sand goby Pomatoschistus minutus. Environmental Biology of Fishes 43, 233-239.

Lande, R. (1981). Models of speciation by sexual selection on polygenic traits. Proceedings of the National Academy of Sciences U.S.A. 78, 3721-3762.

Lande, R. \& Kirkpatrick, M. (1988). Ecological speciation by sexual selection. Fournal of Theoretical Biology 133, 85-98.

Landry, C., Garant, D., Duchesne, P. \& Bernatchez, L. (2001). 'Good genes as heterozygosity': the major histocompatibility complex and mate choice in Atlantic salmon (Salmo salar). Proceedings of the Royal Society of London Series B 268, 1279-1285.

Ligon, J. D. \& Zwartjes, P. W. (1995). Ornate plumage of male red junglefowl does not influence mate choice by females. Animal Behaviour 49, 117-125.

Lindström, K. \& Lundström, J. (2000). Male greenfinches (Carduelis chloris) with brighter ornaments have higher virus infection clearance rate. Behavioral Ecology and Sociobiology 48, 44-51.

Linville, S. U. \& BReitwisch, R. (1997). Carotenoid availability and plumage coloration in wild populations of northern cardinals. Auk 114, 796-800.

Lopez, P. \& Martín, J. (2001). Pheromonal recognition of females takes precedence over the chromatic cue in male Iberian wall lizards. Ethology 107, 901-912.

Lundberg, A. \& Alatalo, R. V. (1992). The Pied Flycatcher. T. \& A.D. Poyser, London.

Luttbeg, B., Towner, M. C., Wandesforde-Smith, A., Mangel, M. \& Foster, S. A. (2001). State-dependent mate-assessment and mate-selection behavior in female threespine sticklebacks (Gasterosteus aculeatus, Gasterosteiformes: Gasterosteidae). Ethology 107, 545-558.

Magnhagen, C. (1991). Predation risk as a cost of reproduction. Trends in Ecology and Evolution 6, 183-186.

Marchetti, K. (1998). The evolution of multiple male traits in the yellow-browed leaf warbler. Animal Behaviour 55, 361-376.

McDonald, D. B. (1989). Correlated of male mating success in a lekking bird with male-male competition. Animal Behaviour 37, 1007-1022.

McGraw, K. J. \& Hill, G. E. (2000). Differential effects of endoparasitism on the expression of carotenoid- and melanin-based ornamental coloration. Proceedings of the Royal Society of London Series B 267, 1525-1531.

McLennan, D. A. (1991). Integrating phylogeny and experimental ethology - from pattern to process. Evolution 45, 1773-1789.

McLennan, D. A. (1996). Integrating phylogenetic and experimental analyses: the evolution of male and female nuptial coloration in the stickleback fishes (Gasterosteidae). Systematic Biology 45, 261-277.

McLennan, D. A. \& McPhaIl, J. D. (1990). Experimental investigations of the evolutionary significance of sexually dimorphic nuptial colouration in Gasterosteus aculeatus (L.): the relationship between male colour and female behaviour. Canadian fournal of Zoology 68, 482-492.

Møller, A. P. \& Alatalo, R. V. (1999). Good-genes effects in sexual selection. Proceedings of the Royal Society of London Series B $\mathbf{2 6 6}$, 85-91.

Møller, A. P., Biard, C., Blount, J. D., Houston, D. C., Ninni, P., Saino, N. \& Surai, P. F. (2000). Carotenoid-dependent signals: indicators of foraging efficiency, immunocompetence or detoxification ability? Avian and Poultry Biology Reviews 11, $137-159$

Møller, A. P. \& Jennions, M. D. (2001). How important are direct fitness benefits of sexual selection. Naturwissenschaften $\mathbf{8 8}$, 401-415.

Møller, A. P. \& Pomiankowski, A. (1993). Why have birds got multiple sexual ornaments? Behavioral Ecology and Sociobiology 32, 167-176.

Møller, A. P., Saino, N., Taramino, G., Galeotti, P. \& Ferrario, S. (1998). Paternity and multiple signaling: effects of a secondary sexual character and song on paternity in the barn swallow. American Naturalist 151, 236-242.

Møller, A. P. \& Swaddle, J. P. (1997). Asymmetry, Developmental Stability and Sexual Selection. Oxford University Press, Oxford. 
Murphy, G. G. \& Gerhardt, H. C. (2000). Mating preference functions of individual female barking treefrogs, Hyla gratiosa, for two properties of male advertisement calls. Evolution 54, 660-669.

Olson, V. \& Owens, I. P. F. (1998). Costly sexual signals: are carotenoids rare, risky or required. Trends in Ecology and Evolution 13, 514 .

OMLand, K. E. (1996a). Female mallard mating preferences for multiple male ornaments. I. Natural variation. Behavioral Ecology and Sociobiology 39, 353-360.

OmLand, K. E. (1996b). Female mallard mating preferences for multiple male ornaments. II. Experimental variation. Behavioral Ecology and Sociobiology 39, 361-366.

Panhuis, T. M., Butlin, R., Zuk, M. \& Tregenza, T. (2001). Sexual selection and speciation. Trends in Ecology and Evolution 16, 364-371.

Parker, G. A. \& Partridge, L. (1998). Sexual conflict and speciation. Philosophical Transactions of the Royal Society of London Series B 353, 261-274.

Partridge, L. \& Hill, W. G. (1984). Mechanisms for frequencydependent mating success. Biological Journal of the Linnean Society 23, 113-132.

Penn, D. J. \& Potts, W. K. (1999). The evolution of mating preferences and major histocompatibility complex genes. American Naturalist 153, 145-164.

Pfennig, K. S. (1998). The evolution of mate choice and the potential for conflict between species and mate-quality recognition. Proceedings of the Royal Society of London Series $B$ 265, 1748.

Pfennig, K. S. (2000). Female spadefoot toads compromise on mate quality to ensure conspecific matings. Behavioral Ecology 11, 220-227.

Pitnick, S., Brown, W. D. \& Miller, G. T. (2001). Evolution of female remating behaviour following experimental removal of sexual selection. Proceedings of the Royal Society of London Series B $\mathbf{2 6 8}$, 557-563.

Pomiankowski, A. \& Iwasa, Y. (1993). Evolution of multiple sexual preferences by Fisher's runaway process of sexual selection. Proceedings of the Royal Society of London Series B 253, 173-181.

Pomiankowski, A. \& Iwasa, Y. (1998). Runaway ornament diversity caused by Fisherian sexual selection. Proceedings of the National Academy of Sciences U.S.A. 95, 5106-5111.

Price, T. (1984). Sexual selection on body size, territory, and plumage variables in a population of Darwin's finches. Evolution 38 , 327-341.

Prum, R. O. (1990). Phylogenetic analysis of the evolution of display behavior in the neotropical manakins (Aves, Pipridae) Ethology 84, 202-231.

Prum, R. O. (1997). Phylogenetic tests of alternative intersexual selection mechanisms: trait macroevolution in a polygynous clade (Aves: Pipridae). American Naturalist 149, 668-692.

Rand, A. S., Ryan, M. J. \& Wilczynski, W. (1992). Signal redundancy and receiver permissiveness in acoustic mate recognition by the tungara frog, Physalaemus pustulosus. American Zoologist 32, 81-90.

REAL, L. (1990). Search theory and mate choice: I. Models of single-sex discrimination. American Naturalist 136, 376-405.

Reid, M. L. \& Weatherhead, P. J. (1990). Mate-choice criteria of Ipswich sparrows - the importance of variability. Animal Behaviour 40, 538-544.

Reynolds, J. D. (1993). Should attractive individuals court more? Theory and a test. American Naturalist 141, 914-927.
Reynolds, J. D. \& Gross, M. R. (1990). Costs and benefits of female mate choice: is there a lek paradox? American Naturalist 136, 230-243.

Rice, W. R. (1996). Sexually antagonistic male adaptation triggered by experimental arrest of female evolution. Nature 381, $232-234$

Rice, W. R. \& Holland, B. (1999). Reply to comments on the chase-away model of sexual selection. Evolution 53, 302-306.

Rosenthal, G. G. \& Servedio, M. R. (1999). Chase-away sexual selection: resistance to 'resistance'. Evolution 53, 296-299.

Rowe, C. (1999). Receiver psychology and the evolution of multicomponent signals. Animal Behaviour 58, 921-931.

Rowe, C. (2002). Sound improves visual discrimination learning in avian predators. Proceedings of the Royal Society of London Series $B$ 269, 1353-1357.

Ryan, M.J. \& RAND, A. S. (1993a). Sexual selection and signal evolution: the ghost of biases past. Philosophical Transactions of the Royal Society of London Series B 340, 187-195.

Ryan, M. J. \& Rand, A. S. (1993b). Species recognition and sexual selection as a unitary problem in animal communication. Evolution 47, 647-657.

Ryan, M.J. \& WAGNER, W. E. J. (1987). Asymmetries in mating preferences between species: female swordtails prefer hererospecific males. Science 236, 595-597.

Rybak, F., Sureau, G. \& Aubin, T. (2002). Functional coupling of acoustic and chemical signals in the courtship behaviour of the male Drosophila melanogaster. Proceedings of the Royal Society of London Series B 269, 695-701.

Scheffer, S. J., Uetz, G. W. \& Stratton, G. E. (1996). Sexual selection, male morphology, and the efficiency of courtship signalling in two wolf spiders (Aranae: Lycosidae). Behavioral Ecology and Sociobiology 38, 17-23.

Scheuber, H., Jacot, A. \& Brinkhof, M. W. G. (2003). Condition-dependence of a multi-component sexual signal in the field cricket Gryllus campestris. Animal Behaviour, in press.

Schluter, D. \& Price, T. (1993). Honesty, perception and population divergence in sexually selected traits. Proceedings of the Royal Society of London Series B 253, 117-122.

SEarcy, W. A. (1992). Song repertoire size and female preferences in song sparrows. American Zoologist 32, 71-80.

Seehausen, O. \& Alphen, J.J. M. (1998). The effect of male coloration on female mate choice in closely related Lake Victoria cichlids (Haplochromis neyrerei complex). Behavioral Ecology and Sociobiology 42, 1-8.

Seehausen, O., Alphen, J.J. M. \& Witte, F. (1997). Cichlid fish diversity threatened by eutrophication that curbs sexual selection. Science 277, 1808-1811.

Senar, J. C. (1999). Plumage coloration as a signal of social status. Proceedings of the International Ornithological Congress 22, 1669-1686.

Sheldon, B. C. (2000). Differential allocation: tests, mechanisms and implications. Trends in Ecology and Evolution 15, 397-402.

Sheldon, B. C. \& Ellegren, H. (1999). Sexual selection resulting from extrapair paternity in collared flycatchers. Animal Behaviour 57, 285-298.

Sheldon, B. G., Merilä, J., Qvarnström, A., Gustafsson, L. \& Ellegren, H. (1997). Paternal genetic contribution to offspring condition predicted by size of male secondary sexual character. Proceedings of the Royal Society of London Series B 264, 297-302.

Shine, R. \& Mason, R. T. (2001). Courting male garter snakes (Thamnophilis sirtalis parietalis) use multiple cues to identify potential mates. Behavioral Ecology and Sociobiology 49, 465-473. 
Slagsvold, T. \& Lifjeld, J. T. (1992). Plumage color is a condition-dependent sexual trait in male pied flycatchers. Evolution 46, 825-828.

Soler, J. J., Guervo, J. J., Møller, A. P. \& deLope, F. (1998). Nest building is a sexually selected behaviour in the barn swallow. Animal Behaviour 56, 1435-1442.

Sorenson, L. G. \& Derrickson, S. R. (1994). Sexual selection in the northern pintail (Anus acuta): the importance of female choice versus male-male competition in the evolution of sexually selected traits. Behavioral Ecology and Sociobiology 35, 389-400.

Strecker, U. \& Kodric-Brown, A. (1999). Mate recognition systems in a species flock of Mexican pupfish. Fournal of Evolutionary Biology 12, 927-935.

Strecker, U. \& Kodric-Brown, A. (2000). Mating preferences in a species flock of Mexican pupfishes (Cyprinodon, Teleostei). Biological Journal of the Linnean Society 71, 677-687.

Suk, H. Y. \& Choe, J. C. (2002). Females prefer males with larger first dorsal fins in the common freshwater goby. Fournal of Fish Biology 61, 899-914.

Sullivan, M. S. (1994). Mate choice as an information gathering process under a time constraint: implications for signal design. Animal Behaviour 47, 141-151.

Taylor, P. W., Hasson, O. \& Clark, D. L. (2000). Body postures and patterns as amplifiers of physical condition. Proceedings of the Royal Society of London Series B 267, 917-922.

Thornhill, R. \& Møller, A. P. (1998). The relative importance of size and asymmetry in sexual selection. Behavioral Ecology 9, 546-551.

Tregenza, T. \& Wedell, N. (2000). Genetic compatibility, mate choice and patterns of parentage: invited review. Molecular Ecology 9, 1013-1027.

Trivers, R. L. (1972). Parental investment and sexual selection. In Sexual Selection and the Descent of Man 1871-1971 (ed. B. Campbell), pp. 136-179. Heinemann, London.

Turelli, M., Barton, N. H. \& Coyne, J. A. (2001). Theory and speciation. Trends in Ecology and Evolution 16, 330-343.

Turner, G. F. \& Burrow, M. T. (1995). A model of sympatric speciation by sexual selection. Proceedings of the Royal Society of London Series B 260, 287-292.
Uy, J. A. \& Borgia, G. (2000). Sexual selection drives rapid divergence in bowerbird display traits. Evolution 54, 273-278.

Wagner, W. E. J. \& Reiser, M. G. (2000). The importance of calling song and courtship song in females mate choice in the variable field cricket. Animal Behaviour 59, 1219-1226.

Wedekind, C. (1992). Detailed information about parasites revealed by sexual ornamentation. Proceedings of the Royal Society of London Series B 247, 169-174.

Welch, A. M., Semlitsch, R. D. \& Gerhardt, H. C. (1998). Call duration as an indicator of genetic quality in male gray tree frogs. Science 280, 1928-1930.

Widemo, F. \& SAether, S. A. (1999). Beauty is in the eye of the beholder: causes and consequences of variation in mating preferences. Trends in Ecology and Evolution 14, 26-31.

WiEns, J.J. (2000). Reconstructing phylogenies from allozyme data: comparing method performance with congruence. Biological Journal of the Linnean Society 70, 613-632.

Wiley, R. H. (1994). Errors, exaggerations and deception in animal communication. In Behavioural Mechanisms in Evolutionary Ecology (ed. L. A. Real), pp. 157-189. University of Chicago Press, Chicago.

Williams, J. \& Lenington, S. (1993). Factors modulating preferences of female house mice for male differing in t-complex genotype - role of t-complex genotype, genetic background, and estrous condition of females. Behavior Genetics 23, 51-58.

WiLson, A. B. (2000). Incipient speciation in sympatric Nicaraguan crater lake cichlid fishes: sexual selection versus ecological diversification. Proceedings of the Royal Society of London Series B 267, 2133-2141.

ZaHAvi, A. (1975). Mate selection - a selection for a handicap. Fournal of Theoretical Biology 53, 205-214.

Zuk, M., Ligon, J. D. \& Thornhill, R. (1992). Effects of experimental manipulation of male secondary sexual characters on female mating preferences in red jungle fowl. Animal Behaviour 44, 999-1006.

Zuk, M., Thornhill, R., Ligon, J. D., Johnson, K., Austad, S., Ligon, S. H., Thornhill, N. W. \& Costin, C. (1990). The role of male ornaments and courtship behavior in female mate choice of red jungle fowl. American Naturalist 136, 459-473. 